\title{
Rare Manifestations of Hydatid Disease
}

\author{
Helena Ribeiro Cátia Leitão António Banhudo \\ Gastroenterology Department, Amato Lusitano Hospital, Castelo Branco, Portugal
}

\section{Keywords}

Hydatid cyst · Liver · Portal hypertension · Inferior vena cava Chronic thrombosis

\section{Manifestações raras da Hidatidose}

\section{Palavras Chave}

Quisto hidático · fígado · hipertensão portal · veia cava inferior · trombose crónica

A 77-year-old man with a past medical history of hydatid cyst of the liver presented to the gastroenterology department as an outpatient with recurrent abdominal pain. Almost 30 years ago, he had refused surgical removal of the hydatid cyst and was being chronically medicated with 1-month cycles of albendazole. At presentation, a physical examination revealed a globose abdomen with exuberant dilated and tortuous varices in the anterior and right abdominal wall with a cephalic flow (Fig. 1) and an upper abdominal palpable mass.

Laboratory tests showed thrombocytopenia $(95,000$ platelets $/ \mu \mathrm{L})$, increased alkaline phosphatase $(281 \mathrm{U} / \mathrm{L})$, $\gamma$-glutamyl transferase (203 U/L), and total bilirubin (2.6 $\mathrm{mg} / \mathrm{dL}$ ), and an international normalized ratio of 1.26 .

\section{KARGER}

E-Mail karger@karger.com www.karger.com/pjg (c) 2017 Sociedade Portuguesa de Gastrenterologia Published by S. Karger AG, Basel

Karger

Open access

This article is licensed under the Creative Commons AttributionNonCommercial-NoDerivatives 4.0 International License (CC BYNC-ND) (http://www.karger.com/Services/OpenAccessLicense). Usage and distribution for commercial purposes as well as any distribution of modified material requires written permission.
Ultrasound and computed tomography revealed mild peritoneal fluid, an enlarged left hepatic lobe, and multiple large hydatid cysts, one located in the liver and the others disseminated in the abdominal and pelvic cavities. The larger hydatid cyst, measuring $20 \times 15 \mathrm{~cm}$, had a right subphrenic location and was occupying the right hepatic lobe. The other hydatid cysts, also with inactive features, were located in the epigastrium, left hypochondrium, and peritoneum with a periumbilical location, and there was one multiloculate hydatid cyst in the pelvic cavity (Fig. 2). The inferior vena cava (IVC) was compressed by the upper abdominal cysts at the level of the suprahepatic veins and had signs of chronic thrombosis from this level until the emergence of the renal veins, forming venous collaterals to the anterior abdominal wall (Fig. 3). Immunoglobulin (Ig) G anti-Echinococcus granulosus antibodies were positive and IgM was negative. Upper gastric endoscopy revealed small esophageal varices and congestive gastric mucosa suggestive of portal hypertensive gastropathy, and there was evident extrinsic compression in the duodenal bulb (Fig. 4). The patient declined invasive treatment and initiated medical therapy.

Hydatid disease is a zoonosis caused by infection with the larval stage of the E. granulosus tapeworm. This is a considerable health problem in endemic areas, namely, in Mediterranean and African countries. Human infection with E. granulosus causes the development of one or more 
Fig. 1. Exuberant dilated and tortuous varices in the anterior and right abdominal wall.
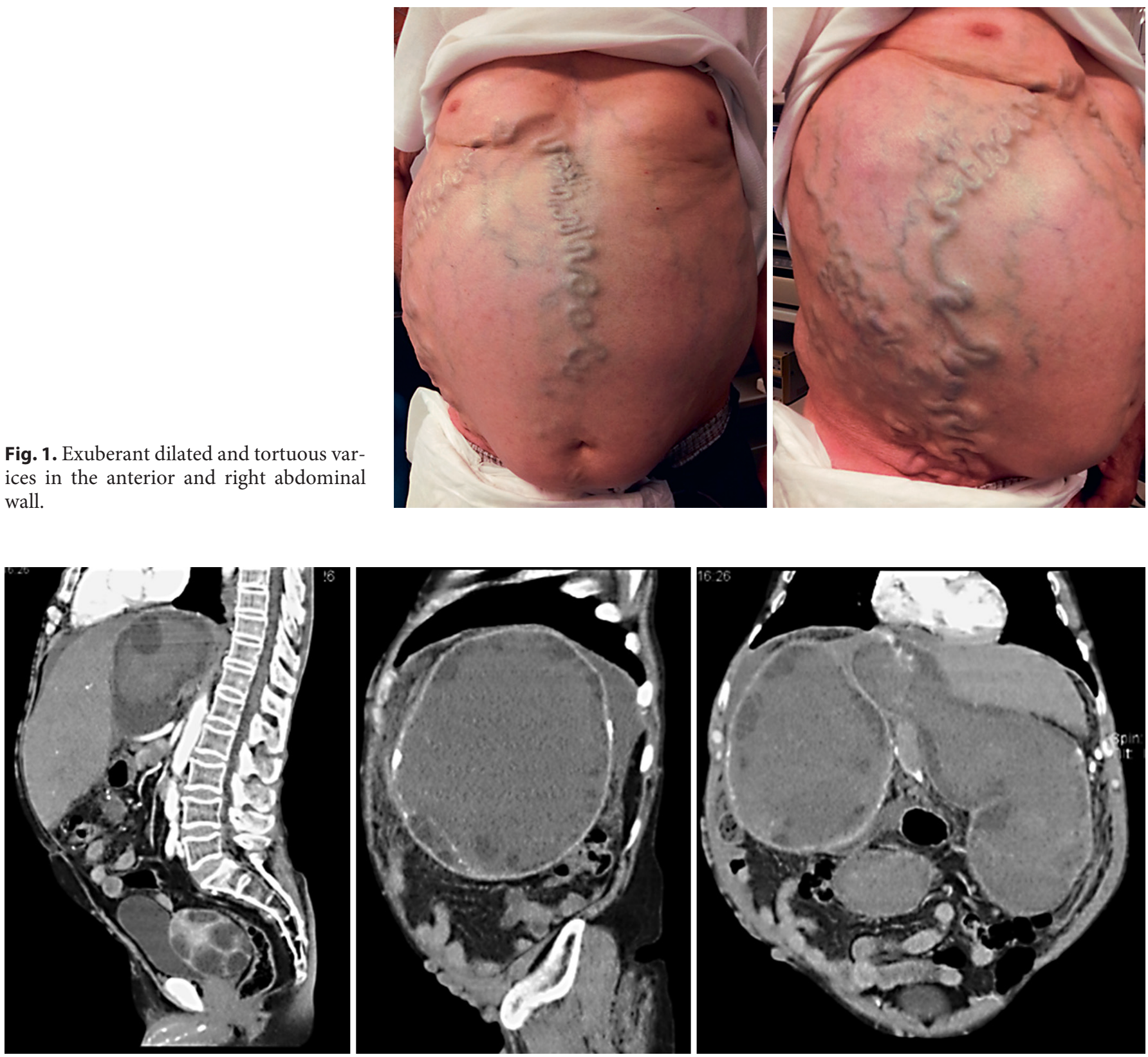

Fig. 2. Computed tomography images showing an enlarged left hepatic lobe and multiple large hydatid cysts, one located in the liver and the others disseminated in the abdominal and pelvic cavities.

hydatid cysts that most commonly affect the liver followed by the lungs. Hydatid disease is frequently asymptomatic, although it can be associated with abdominal pain, nausea, and vomiting. Other symptoms depend on the size and location of the cysts and the pressure exerted on the surrounding structures [1]. Hydatid cysts tend to slowly grow towards the hepatic surface and sometimes can replace an entire liver lobe. Furthermore, if the cysts compress the IVC at the level of the hepatic veins, they may be a cause of posthepatic portal hypertension [2]. Another rare complication of hydatid disease is the presence of hydatid cysts disseminated in the peritoneal cavity. This usually results from the spontaneous or iatrogenic rupture of hepatic cysts into the peritoneum. Although it can be related with severe manifestations like anaphylactic reactions, it can be also asymptomatic $[3,4]$. 


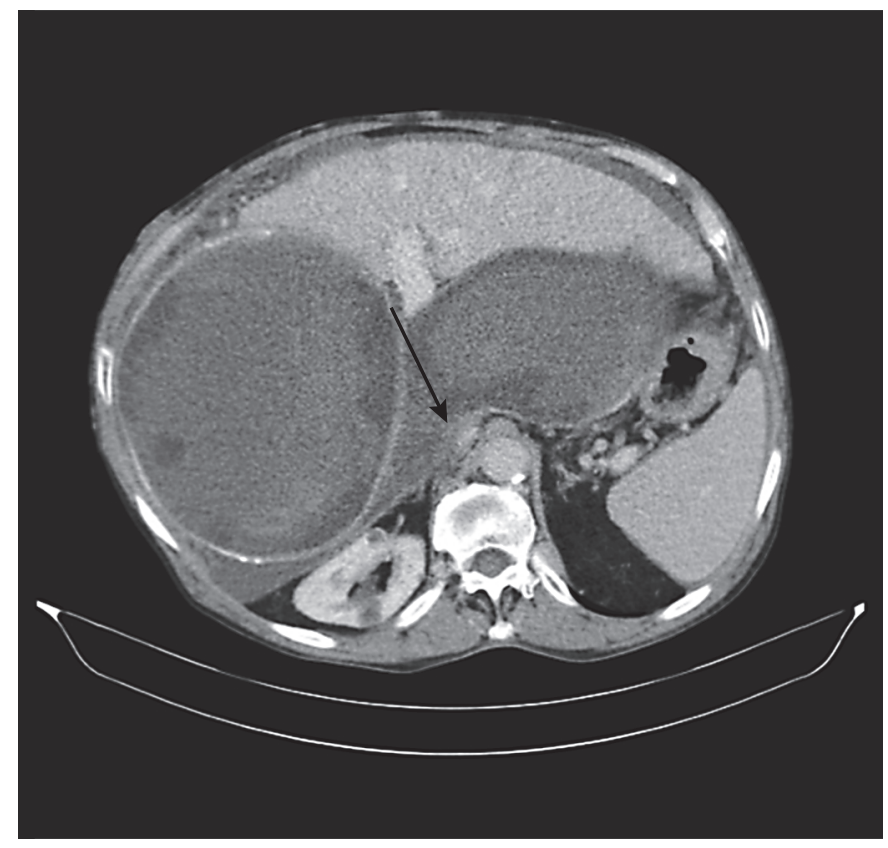

Fig. 3. Computed tomography image of the inferior vena cava (arrow) compressed by the upper abdominal cysts.

We report a case of hydatid disease of the liver with disseminated peritoneal cysts complicated with chronic thrombosis of the IVC and portal hypertension. These complications result from the mass effect of slowly enlarging giant cysts. The cysts had caused the progressive compression of the IVC, allowing the development of venous collaterals. The thrombosis of the IVC and the intrinsic and extrinsic compression of the hepatic parenchyma induced by the cysts caused hepatic and posthepatic portal hypertension [2]. These complex clinical manifestations are rare and were possible to have developed due to the several years of evolution of the hydatid cysts in our patient.

\section{Statement of Ethics}

This study did require neither informed consent nor review/ approval by the appropriate ethics committee.

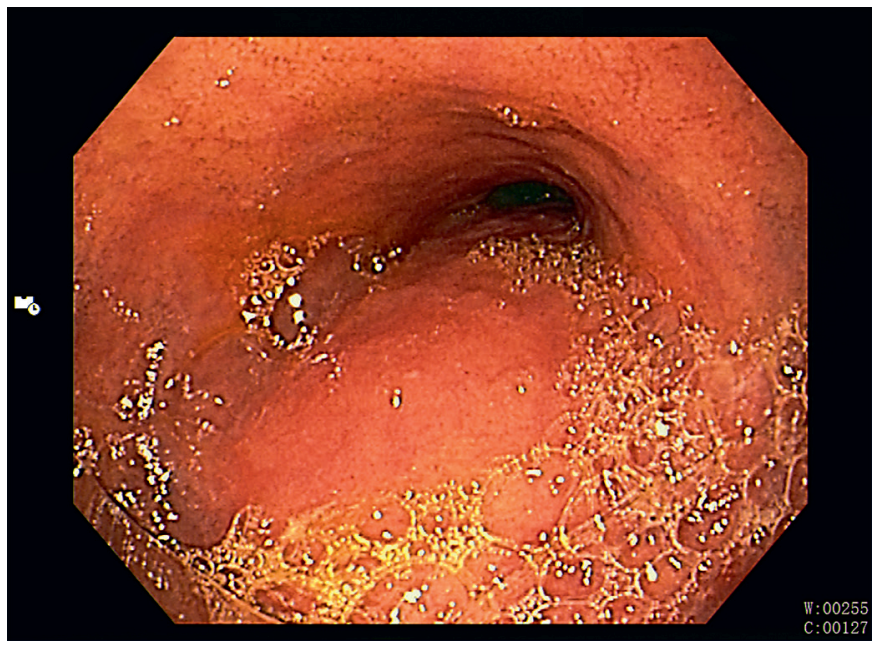

Fig. 4. Endoscopic image of upper gastric endoscopy showing extrinsic compression in the duodenal bulb.

\section{Disclosure Statement}

The authors declare no conflicts of interest.

\section{Author Contributions}

Helena Ribeiro: drafting of the manuscript, literature search, and first author; Cátia Leitão: drafting of the manuscript and literature search; António Banhudo: critical revision of the manuscript and final approval.

\footnotetext{
References $\quad 1$ Moro P, Schantz PM: Echinococcosis: a review. Int J Infect Dis 2009;13:125-133.

2 Agarwal N, Kumar S: Budd-Chiari syndrome owing to liver hydatid disease: case report and review of the literature. Ann Trop Paediatr 2009;29:301-304.

3 Lianos GD, Lazaros A, Vlachos K, Georgiou GK, Harissis HV, Mangano A, et al: Unusual locations of hydatid disease: a 33 year's experience analysis on 233 patients. Updates Surg 2015;67:279-282.

4 Prousalidis J, Tzardinoglou K, Sgouradis L, Katsohis C, Aletras H: Uncommon sites of hydatid disease. World J Surg 1998;22:17-22.
} 